\title{
LA JURISPRUDENCIA CONSTITUCIONAL COLOMBIANA EN 2016: DERECHOS SEXUALES Y REPRODUCTIVOS DE LAS MUJERES EN CONDICIÓN DE DISCAPACIDAD Y SOBRE SEGUNDOS OCUPANTES EN PROCESOS DE RESTITUCIÓN DE TIERRAS
}

The Colombian Constitutional Jurisprudence in 2016: Sexual and reproductive rights of women in disability condition and over "second occupants" in land restitution process

\author{
PAULA ROBLEDO SILVA ${ }^{1}$ \\ Universidad Externado de Colombia \\ paula.robledo@uexternado.edu.co \\ SNEITHER CIFUENTES ${ }^{2}$ \\ Universidad Nacional de Colombia \\ secifuentesc@unal.edu.co
}

Cómo citar/Citation

Robledo Silva, P. y Cifuentes, S. (2017).

La jurisprudencia constitucional colombiana en 2016 :

derechos sexuales y reproductivos de las mujeres en condición de discapacidad y sobre segundos ocupantes en procesos de restitución de tierras. Anuario Iberoamericano de Justicia Constitucional, 21, 279-301.

doi: https://doi.org/10.18042/cepc/aijc.21.11

1 Abogada egresada de la Universidad Externado de Colombia, especialista en Derecho Constitucional y Ciencia Política del Centro de Estudios Políticos y Constitucionales de Madrid, magíster en Derecho Público de la Universidad Externado de Colombia y doctora en Derecho por la Universidad de Valladolid. Actualmente, defensora delegada para los Asuntos Constitucionales y Legales de la Defensoría del Pueblo, docente e investigadora de la Universidad Externado de Colombia y miembro del Consejo Directivo de la Facultad de Derecho de dicha universidad.

2 Abogado egresado de la Universidad Nacional de Colombia, magíster en Derechos Humanos de la Universidad Nacional de Colombia. Actualmente, asesor Defensoría Delegada para los Asuntos Constitucionales y Legales de la Defensoría del Pueblo de Colombia. 


\section{SUMARIO}

I. INTRODUCCIÓN. II. LOS DERECHOS SEXUALES Y REPRODUCTIVOS DE LAS MUJERES EN CONDICIÓN DE DISCAPACIDAD EN COLOMBIA: 1. La sentencia T-573 de 2016. 2. El reconocimiento de la capacidad jurídica un avance en los derechos sexuales y reproductivos de las mujeres en condición de discapacidad. III. EL DEBER DE PROTECCIÓN SOBRE LOS SEGUNDOS OCUPANTES EN LOS PROCESOS DE RESTITUCIÓN DE TIERRAS: 1. La sentencia C-330 de 2016. 2. Una decisión garantista para evitar una lucha entre iguales. BIBLOGRAFíA.

\section{INTRODUCCIÓN}

Este escrito presenta una crónica de dos sentencias que, a nuestro juicio, consideramos forman parte de los avances más relevantes dentro de la jurisprudencia de la Corte Constitucional colombiana durante el año 2016. Siguiendo la misma estructura utilizada en ediciones anteriores, hemos seleccionado una de tutela (T-573) y otra de constitucionalidad (sentencia C-330).

La primera, analizará un caso reciente de la jurisprudencia constitucional colombiana sobre los derechos sexuales y reproductivos de las mujeres en condición de discapacidad y su capacidad jurídica, con una relevancia tal que constituye un giro de la jurisprudencia que la misma corporación venía desarrollando desde 2002; la segunda, presentará una explicación del pronunciamiento de la Corte respecto de la problemática generada con la ocupación secundaria en los procesos de restitución de tierras, cuando el desalojo de personas distintas a las víctimas reclamantes es necesario con el fin de facilitar la recuperación oportuna y efectiva del predio.

De tal forma, en este escrito se pretende dar cuenta, de una parte, del avance jurisprudencial en el reconocimiento de la capacidad jurídica y la especial condición de la mujer en situación de discapacidad, expuesta normalmente a barreras jurídicas y sociales que impactan negativamente en el goce efectivo de sus derechos; y de otra parte, de la respuesta dada por el Alto Tribunal a la problemática de la ocupación secundaria, partiendo de identificar la existencia de una discriminación indirecta sobre los segundos ocupantes, cuando estos demostraran condiciones de vulnerabilidad, y no hubieran 
tenido relación directa o indirecta con el despojo o abandono forzado de las tierras objeto de la solicitud de restitución.

La importancia de ambas decisiones está dada en términos de ampliar el marco de referencia para la interpretación de las y los jueces constitucionales en nuestro país, al momento de resolver casos que comprometen los derechos sexuales y reproductivos de las mujeres en condición de discapacidad y los derechos de las víctimas de desplazamiento forzado en relación con la política de restitución de tierras, establecida mediante la Ley 1448 de 2011.

\section{LOS DERECHOS SEXUALES Y REPRODUCTIVOS DE LAS MUJERES EN CONDICIÓN DE DISCAPACIDAD EN COLOMBIA}

La discapacidad es una condición que define, dentro de otros factores, la identidad de las personas y la forma de relacionarse con los demás. Genera estereotipos y condicionamientos sociales para aquellos que la padecen y afecta de manera diferente tanto a hombres como a mujeres. El ejercicio de los derechos fundamentales bajo las barreras que la sociedad impone a las personas con diversidad funcional es mucho más difícil que para aquellos individuos que son considerados generalmente como «no discapacitados».

Ello ha llevado a que, tanto el derecho internacional, como los ordenamientos jurídicos nacionales, se hayan encargado de proteger los derechos de las personas en condición de discapacidad. Así mismo, se han impuesto obligaciones a cargo de los Estados con el objetivo de que se brinde el apoyo y se creen las medidas necesarias para que las personas con diversidad funcional puedan ejercer sus derechos en condiciones de igualdad. En esa medida, sin lugar a dudas, es posible afirmar que uno de los instrumentos internacionales más importantes en esta materia es la Convención sobre los Derechos de las Personas con Discapacidad de la Asamblea General de la Naciones Unidas de 2006.

De ahí la importancia de analizar los avances de la Corte Constitucional colombiana en materia de discapacidad. Así, este Alto Tribunal en la sentencia de tutela objeto de estudio resuelve con base en la Convención sobre los Derechos de las Personas con Discapacidad, ratificada por Colombia en mayo de 2011, proteger los derechos sexuales y reproductivos de una menor en condición de discapacidad, apartándose de la jurisprudencia que hasta el momento había desarrollado la misma corporación, para, en su lugar, adoptar una posición mucho más garantista y conforme a los postulados constitucionales y convencionales.

En este orden, se analizará la institución de la capacidad jurídica, los derechos sexuales y reproductivos de las mujeres en condición de discapacidad y 
se resaltará la relevancia que tiene la sentencia para la aplicación real y correcta de la Convención sobre los Derechos de las Personas con Discapacidad en Colombia (en adelante: la Convención).

\section{LA SENTENCIA T-573 DE 2016}

En octubre de 2015, la madre de Silvia una menor de quince años que padecía síndrome de Down e hipertiroidismo interpuso una acción de tutela para que se protegieran los derechos de su hija a la salud, la vida, la integridad física y la seguridad social, porque había sufrido diversas dolencias (períodos menstruales prolongados, náuseas, dolores abdominales y de cabeza) desde que se le implantó el dispositivo anticonceptivo Jadelle en octubre de 2014. La pretensión de la accionante consistió en que se le ordenara a la unidad hospitalaria AA, que le implantó el dispositivo, que se lo retirara y en su reemplazo le realizara el procedimiento quirúrgico de anticoncepción definitiva denominado tubectomía.

La unidad hospitalaria AA y CC EPS no se pronunciaron sobre la acción de tutela, mientras que la empresa social del Estado XX se opuso a la misma, argumentando que había prestado todos los servicios de salud de primer nivel requeridos. La empresa señaló que le había brindado tanto a la accionante como a su hija la información necesaria sobre los métodos anticonceptivos existentes y sobre la autorización judicial que debían obtener para la práctica de la tubectomía, autorización esta que en últimas conllevaba la sustitución del consentimiento de la menor.

El juzgado de instancia denegó el amparo al considerar que la madre no demostró haber obtenido la autorización judicial requerida para que se practicara la tubectomía. No obstante, consideró que la negativa de retirar el dispositivo anticonceptivo Jadelle vulneraba los derechos de la menor y, en consecuencia, ordenó remitir a Silvia a un especialista para que determinara la conveniencia de retirar el dispositivo subdérmico y dictaminara un mecanismo anticonceptivo menos lesivo, que en todo caso no podía ser la esterilización.

La Corte Constitucional se dispuso a resolver dos problemas jurídicos. El primero, relativo a la posible vulneración de los derechos fundamentales a la salud e integridad física de Silvia por las dolencias que tuvo que soportar por la implantación y posterior negativa de la entidad demandada a retirar el dispositivo subdérmico. El segundo, sobre la eventual vulneración de sus derechos a la autonomía, integridad personal y derechos sexuales y reproductivos al ser sustituida su voluntad y desconocer las obligaciones del Estado colombiano derivadas de la ratificación de la Convención sobre los Derechos de las Personas con Discapacidad en el 2011. 
La Corte se ocupó de varios asuntos, entre los que se destacan: i) el modelo social de discapacidad en el marco internacional; ii) los derechos sexuales y reproductivos de las personas en condición de discapacidad; iii) el marco normativo interno sobre dichos derechos; iv) el parámetro de constitucionalidad a utilizar, y v) la resolución del caso concreto.

En primer lugar, la Corte Constitucional aclara que la Convención sobre los Derechos de las Personas con Discapacidad pretendió superar el modelo médico-rehabilitador, según el cual, la discapacidad es una condición médica asociada a la enfermedad y, por ende, requiere tratamiento. La Convención alude a la discapacidad como un concepto en evolución y que «resulta de la interacción entre las personas con deficiencias y las barreras debidas a la actitud y al entorno que evitan su participación plena y efectiva en la sociedad, en igualdad de condiciones con las demás» ${ }^{3}$. En otras palabras, para la Convención, la discapacidad no es una enfermedad, sino que es una construcción social que ubica a determinadas personas en una posición de inferioridad respecto de otras, se trata de relaciones de poder y de barreras u obstáculos que impone la sociedad a personas que por su diversidad funcional no interactúan con su entorno en las mismas condiciones que lo hacen los demás individuos.

Al ratificar la Convención en mayo de 20114, el Estado colombiano se comprometió a incorporar a su ordenamiento jurídico el modelo social de discapacidad y, con ello, reconocer la capacidad jurídica de las personas en condición de discapacidad. Por vía del art. 12 de la Convención se adopta el principio «nada sobre nosotros sin nosotros», que implica reconocer que las personas en condición de discapacidad tienen derecho a decidir por sí mismas sobre todos los aspectos que les concierne. El máximo tribunal constitucional colombiano habla, entonces, de un modelo social que reconoce la capacidad jurídica que tienen todas las personas en condición de discapacidad para tomar decisiones informadas en todos los aspectos de su vida.

En segundo lugar, la Corte señala que la Convención no trae una lista de derechos específicos de los que sean titulares las personas en condición de discapacidad, sino que dispone una serie de obligaciones que asumen los Estados parte con el fin de adoptar las medidas necesarias para eliminar las barreras sociales que les impiden ejercer en igualdad de condiciones los mismos derechos que tienen las demás personas. Las obligaciones que establece

3 Así lo indica el literal e) del preámbulo de la Convención sobre los Derechos de las Personas con Discapacidad, adoptada por la Asamblea General de la Naciones Unidas el 13 de diciembre de 2006.

4 La Convención fue aprobada a través de la Ley 1346 de 2009, declarada constitucional por la Corte en Sentencia C-293 de 2010 y ratificada el 10 de mayo de 2011. 
la Convención pueden clasificarse como obligaciones de respeto, de protección y de cumplimiento. Las obligaciones de respeto consisten en modificar las leyes, reglamentos, prácticas y costumbres que constituyan discriminación contra las personas en condición de discapacidad y en abstenerse de incumplir la Convención. Las obligaciones de protección incluyen tomar medidas para evitar que organizaciones, empresas, particulares y autoridades estatales incurran en discriminación por motivos de discapacidad. Y las obligaciones de cumplimiento implican adoptar medidas legislativas, administrativas y de cualquier otra índole para hacer efectivos los derechos reconocidos en la Convención.

En tercer lugar, respecto al marco normativo interno, la Corte hace mención de su jurisprudencia sobre los derechos sexuales y reproductivos de las personas en condición de discapacidad desde el 2002. Separa aquellas sentencias entre las proferidas con anterioridad y con posterioridad a la ratificación de la Convención. Resalta que con anterioridad a la ratificación, sus fallos seguían el modelo médico-rehabilitador de la discapacidad y, se avalaba la esterilización con autorización judicial por la vía del consentimiento sustituto cuando se acreditara medicamente que no existía posibilidad de que en un futuro la persona pudiera recuperarse $e^{5}$. Mientras que, en las sentencias posteriores a la ratificación de la Convención ${ }^{6}$, si bien se ve una tendencia a darle mayor importancia al consentimiento de la persona discapacitada, se sigue fallando de acuerdo al modelo médico-rehabilitador.

En cuarto lugar, apartándose de las sentencias anteriores por no ser aplicables al caso bajo examen, la Corte define el parámetro de constitucionalidad señalando cuatro fundamentos en los que basará su decisión. Primero, que al suscribir la Convención el Estado colombiano se comprometió a eliminar los sistemas de sustitución de las decisiones de las personas en condición de

5 Decisiones sobre la esterilización de personas en situación de discapacidad que se adoptaron antes de la ratificación de la CDPCD: la Sentencia T-850 de 2002 sobre la figura del consentimiento orientado hacia el futuro; la Sentencia T-248 de 2003 sobre el imperio de la razón médica; la Sentencia T-492 de 2006 sobre la autorización judicial para la esterilización de una persona mayor de edad antes de que haya sido declarada interdicta; y la Sentencia T-1019 de 2006 sobre las etapas para obtener la autorización judicial de una esterilización bajo el modelo médico.

6 Decisiones sobre la esterilización de personas en situación de discapacidad que se adoptaron con posterioridad a la ratificación de la CDPCD: la Sentencia T-063 de 2012 sobre las personas en situación de discapacidad tienen derecho a acceder a información sobre sus derechos sexuales y reproductivos; la Sentencia T-740 de 2014 sobre la obligación estatal de brindar apoyos y ajustes razonables; y la Sentencia T-303 de 2016 que vuelve al modelo médico. 
discapacidad y, en cambio, brindarles los apoyos necesarios para la toma de decisiones autónomas; a respetar sus derechos sexuales y reproductivos; y a garantizar que ninguno sea sujeto de esterilizaciones forzadas que son consideradas formas de tortura por la Convención. Segundo, que mediante la sentencia C-293 de 2010, la Corte declaró que la Convención era conforme a la Constitución Política de Colombia. Tercero, que el Comité de Naciones Unidas sobre los Derechos de las Personas con Discapacidad exigió al Estado colombiano, eliminar la esterilización de personas con discapacidad sin su consentimiento, con autorización del juez y, a revisar las sentencias de la Corte Constitucional que avalan esta práctica, así como derogar las disposiciones que restrinjan total o parcialmente la capacidad jurídica de las personas con discapacidad. Y finalmente, que persisten las barreras sociales que impiden a las personas en condición de discapacidad ejercer sus derechos sexuales y reproductivos plenamente.

Por lo anterior, la Corte concluye en la sentencia que

al ratificar la CDPCD el Estado colombiano reconoció la capacidad jurídica de todas las personas con discapacidad, en igualdad de condiciones con las demás, frente a todos los aspectos de su vida, y que ello implica eliminar cualquier forma de consentimiento sustituto y proporcionarles, en cambio, los ajustes razonables, apoyos y salvaguardias necesarios para que tomen decisiones autónomas. Por lo tanto, ante la ausencia de una manifestación concreta sobre la voluntad de someterse a un procedimiento de esterilización, la intervención no debería realizarse.

En cuarto lugar, la Corte define el parámetro de constitucionalidad de la sentencia bajo análisis a partir de los siguientes cuatro fundamentos de su decisión, los cuales se apartan de su propia jurisprudencia. Primero, que al suscribir la Convención el Estado colombiano se comprometió a eliminar los sistemas de sustitución de las decisiones de las personas en condición de discapacidad y, en cambio, brindarles los apoyos necesarios para la toma de decisiones autónomas; a respetar sus derechos sexuales y reproductivos; y a garantizar que ninguno sea sujeto de esterilizaciones forzadas que son consideradas formas de tortura por la Convención. Segundo, que mediante la sentencia C-293 de 2010, la Corte declaró que la Convención era conforme a la Constitución Política de Colombia. Tercero, que el Comité de Naciones Unidas sobre los Derechos de las Personas con Discapacidad exigió al Estado colombiano, eliminar la esterilización de personas con discapacidad sin su consentimiento, con autorización del juez y, a revisar las sentencia de la Corte Constitucional que avalan esta práctica, así como derogar las disposiciones que restrinjan total o parcialmente la capacidad jurídica de las personas con discapacidad. Y finalmente, que persisten las barreras sociales que impiden 
a las personas en condición de discapacidad ejercer sus derechos sexuales y reproductivos plenamente.

Finalmente, en el caso concreto, la Corte encuentra que, de las pruebas obrantes en el expediente, la vulneración del derecho a la salud de Silvia fue superada, pues el dispositivo subdérmico que le causaba distintas dolencias le fue retirado en diciembre de 2015. El dispositivo fue extraído en cumplimiento de la sentencia del a quo que ordenó la remisión de Silvia a un especialista para que determinara la posibilidad de reemplazarlo por otro anticonceptivo menos lesivo, que debía ser distinto a la esterilización. Sin embargo, la Corte aclara que como no tiene certeza sobre la condición de salud de Silvia actualmente, ordenará unas medidas para garantizar la continuidad de la prestación de los servicios de salud que Silvia pueda requerir.

A pesar de lo anterior, la Corte constata que Silvia no contó con la oportunidad de decidir sobre el implante ni extracción del dispositivo anticonceptivo subdérmico, no tuvo acceso a la información y educación sobre planificación ni reproducción familiar acorde a su edad, no se probó que su opinión haya sido tenida en cuenta para adelantar los trámites para extraer el dispositivo, no se le brindaron los apoyos y ajustes necesarios para que expresara su voluntad y tomara una decisión libre e informada. Todo lo anterior provocó la vulneración de sus derechos sexuales y reproductivos, su derecho a la dignidad humana, al libre desarrollo de la personalidad, a la igualdad y a la integridad física porque, en breve, el consentimiento de Silvia fue sustituido frente a la extracción del dispositivo subdérmico.

Sobre la pretensión de la madre de Silvia de que se ordenara la práctica de un procedimiento de anticoncepción definitiva, la Corte señala que mientras Silvia sea menor de edad, en razón de la prohibición del art. 7 de la Ley 1412 de $2010^{7}$, no puede ser sometida a tal procedimiento. Aclara también que el hecho de que Silvia alcance la mayoría de edad tampoco lleva a que se le pueda esterilizar sin su consentimiento, pues todas las personas en condición de discapacidad tienen capacidad jurídica y para tomar sus decisiones. El Estado debe brindarle la orientación necesaria y suficiente para decidir, aunque en caso de querer someterse a un procedimiento de esterilización definitivita, señala la Corte que su consentimiento libre e informado debe ser manifestado en un proceso judicial.

En consecuencia, la Corte resuelve confirmar parcialmente la sentencia del ad quo en tanto denegó la práctica de la intervención quirúrgica a la

\footnotetext{
Art. 7. Prohibición. En ningún caso se permite la práctica de la anticoncepción quirúrgica a menores de edad. Artículo declarado exequible por la Corte Constitucional mediante Sentencia C-131 de 2014.
} 
menor, pero por razones diferentes a las que dio el juzgado. Como se expuso anteriormente, la Corte sí consideró que se vulneraron los derechos sexuales y reproductivos de la menor, así como su dignidad humana, libre desarrollo de la personalidad e integridad física, pero se aparta de la jurisprudencia que hasta el momento se sostenía en sede de tutela, según la cual «ante la inexistencia del ejercicio de la autonomía individual, impera la razón médica, dirigida a salvaguardar la vida, salud e integridad del paciente» que la llevó a fallar de acuerdo al modelo médico-rehabilitador durante más de diez años. En contraste, en cumplimiento de las obligaciones y compromisos adquiridos con la ratificación de la Convención, señala que se debe reconocer la capacidad jurídica de las personas en condición de discapacidad y eliminar cualquier forma de consentimiento sustituto y, en su lugar, implementar las medidas pertinentes y brindarles las ayudas necesarias para que puedan tomar decisiones autónomas, libres e informadas.

Para proteger la capacidad jurídica de Silvia de acuerdo a las exigencias de la Convención, la Corte ordena tres «ajustes razonables» ${ }^{8}$ o medidas, con base en los conceptos de dos organizaciones expertas en el tema. Primero, ordena a la EPS que se abstenga de autorizar cualquier procedimiento de anticoncepción definitiva a Silvia que no haya sido consentido por ella y que, en su lugar, brinde todos los apoyos y ajustes razonables para garantizarle el acceso a la información sobre salud sexual y reproductiva de acuerdo a su edad y, que le permita decidir si desea utilizar otro método anticonceptivo. Segundo, ordena a la EPS que integre un equipo interdisciplinario para que se reúnan con Silvia y sus padres, incluso por separado, para identificar las barreras específicas que enfrenta la niña y determinar con ella, los ajustes razonables y apoyos necesarios para que pueda ejercer su capacidad jurídica. Tercero, ordena también a la EPS y a la empresa social del Estado que implementen y financien los ajustes razonables para garantizar que los afiliados con discapacidad accedan a los servicios de salud en iguales condiciones que los demás.

Finalmente, la Corte señala que el Estado colombiano está en deuda de expedir la normatividad que defina de forma clara los apoyos necesarios que los prestadores de servicios de salud deben brindar a las personas en condición de discapacidad. En consecuencia, ordena al Ministerio de Salud y Protección Social que expida la reglamentación que garantice el acceso a la información

8 Los ajustes razonables son definidos en el art. 2 de la Convención como «las modificaciones y adaptaciones necesarias y adecuadas que no impongan una carga desproporcionada o indebida, cuando se requieran en un caso particular, para garantizar a las personas con discapacidad el goce o ejercicio, en igualdad de condiciones con las demás, de todos los derechos humanos y libertades fundamentales». 
adecuada a las personas en condición de discapacidad sobre sus derechos y que aclare las obligaciones de los prestadores de salud en la materia. Y también ordena al Ministerio de Educación Nacional que traduzca el contenido de la sentencia T-573 de 2016 a un formato de lectura fácil que le permita tanto a Silvia como a las personas psicológicamente diversas conocer y comprender la providencia.

\section{EL RECONOCIMIENTO DE LA CAPACIDAD JURÍDICA UN AVANCE EN LOS DERECHOS SEXUALES Y REPRODUCTIVOS DE LAS MUJERES EN CONDICIÓN DE DISCAPACIDAD}

De acuerdo con las consideraciones de la Corte en la sentencia T-573 de 2016, es claro que existe en el ordenamiento jurídico colombiano una incongruencia entre las obligaciones asumidas por el Estado con la ratificación de la Convención y las normas civiles sobre la capacidad jurídica. Como se señaló, el Estado asume la obligación de adoptar el modelo social de discapacidad y reconocer la capacidad jurídica a las personas en condición de discapacidad. Sin embargo, la existencia de figuras como el proceso de interdicción ${ }^{9}$ y la esterilización previa autorización judicial, sin consultar el consentimiento de la persona discapacitada, son una clara contradicción del ordenamiento jurídico colombiano con el instrumento internacional.

La gravedad del asunto no solo radica en el incumplimiento de las obligaciones internacionales asumidas por Colombia, sino en que se trata de una violación de los derechos fundamentales de la población en situación de discapacidad por parte del Estado colombiano, especialmente de las mujeres en quienes confluyen varias situaciones de vulnerabilidad. Los procesos de interdicción en Colombia son conocidos por los jueces de familia y se supone que tienen como finalidad proteger a las personas que carecen de las capacidades mentales o cognoscitivas para administrar personalmente su patrimonio, para ello se declara a una persona «incapaz» de adquirir obligaciones frente a terceros, con lo cual, se entiende protegido su patrimonio (PAIIS, 2014). Sin embargo, la declaratoria de una persona como incapaz implica el despojo de toda su capacidad legal, que consiste en el atributo de poder ser titular de derechos y de ser reconocido como persona jurídica por la ley (PAIIS, 2014),

9 El proceso de interdicción está consagrado en la ley colombiana en el art. 586 del Código General del Proceso. También la Ley 1306 de 2009 trata en integridad otros aspectos de la interdicción porque con ella se dictan «las normas para la Protección de Personas con Discapacidad Mental y se establece el Régimen de la Representación Legal de Incapaces Emancipados». 
y el ejercicio de sus derechos queda en cabeza de un guarda, quien toma - jurídicamente hablando- todas las decisiones del interdicto.

Según el informe de PAIIS (2014), los jueces basan generalmente sus decisiones en el dictamen médico sobre el «nivel de discapacidad» que tiene la persona. Ese dictamen es casi el único fundamento de la decisión de anular jurídicamente a una persona en todas las relaciones que pueda establecer, sin consultar su voluntad ni acudir a otras pruebas. Y esta situación reviste mayor gravedad cuando los procesos de interdicción son usados, en el caso de las mujeres, como un paso previo para solicitar la esterilización (Pons y Sánchez, 2017). El hecho de que la valoración que hacen los jueces en Colombia para declarar la interdicción sea tan superficial, vulnera los derechos fundamentales de las mujeres en condición de discapacidad, en primer lugar, a ejercer la capacidad jurídica en igualdad de condiciones y, en segundo lugar, sus derechos sexuales y reproductivos. Lo que reafirma y evidencia el incumplimiento de la Convención ${ }^{10}$ por parte del Estado colombiano, en cuyo ordenamiento jurídico persiste el paradigma del modelo médico-rehabilitador de discapacidad.

Para ahondar en el tema de la relación entre el reconocimiento de la capacidad jurídica de las mujeres en condición de discapacidad y sus derechos sexuales y reproductivos, se analizarán por separado estos conceptos. Por una parte, la capacidad jurídica se puede entender como el atributo de la personalidad de toda persona que le permite ser titular de derechos, ejercerlos y adquirir obligaciones (Pons y Sánchez, 2017). De aquella definición se debe resaltar que más que un derecho subjetivo, es un atributo inherente a todos los seres humanos. Su desconocimiento implica negar la participación de una persona en las relaciones jurídicas y ello se traduce en un menoscabo de su dignidad humana (Pons y Sánchez, 2017). Así, cuando la ley colombiana ${ }^{11}$ avala la existencia y trámite del proceso de interdicción, la vulneración de los derechos fundamentales es patrocinada por el mismo ordenamiento, específicamente por medio de la posibilidad de sustituir el consentimiento de una persona en condición de discapacidad para practicar la esterilización forzada, con autorización previa del juez ${ }^{12}$.

10 El art. 12 de la Convención obliga a los Estados parte a reconocer la personalidad jurídica de las personas con discapacidad y que tienen capacidad jurídica en igualdad de condiciones que las demás personas en todos los aspectos de su vida.

11 Ley 1306 de 2009 por la cual se dictan normas para la Protección de Personas con Discapacidad Mental y se establece el Régimen de la Representación Legal de Incapaces Emancipados.

12 La Ley 1412 del 2010 por medio de la cual se autoriza la realización de forma gratuita y se promueve la ligadura de conductos deferentes o vasectomía y la ligadura de trompas de Falopio como formas para fomentar la paternidad y la maternidad responsable, 
Por otra parte, para explicar los derechos sexuales y reproductivos de las mujeres a la luz de la interpretación de la Corte Constitucional se debe partir del hecho de que la sexualidad es una dimensión humana y una forma de comunicación (Arnau, 2014). Sin embargo, su ejercicio se dificulta para algunas personas con diversidad funcional, pero no por su "discapacidad» como sinónimo de enfermedad, sino por las barreras, prejuicios y estereotipos a los que la sociedad las somete. Las personas en condición de discapacidad históricamente han sido consideradas como personas asexuadas o, por el contrario, que manifiestan un deseo sexual exacerbado o que no pueden controlar. Y ello lleva a infantilizarlas y relegar a un segundo plano sus derechos sexuales y reproductivos o a considerar que no tienen algún interés en ejercerlos (Arnau, 2014).

No obstante, en diversos instrumentos internacionales ratificados por Colombia que integran el bloque de constitucionalidad, se consagra que los derechos sexuales y reproductivos son derechos fundamentales ${ }^{13}$. Todas las personas son titulares de ellos sin distinción alguna. Son una expresión del derecho a la vida independiente que también se puede denominar derecho al libre desarrollo de la personalidad, pues consiste en la libertad de tomar las decisiones sobre su vida y su participación en comunidad (Arnau, 2014).

En suma, los derechos sexuales y reproductivos, como lo señala la Corte en la sentencia bajo análisis, pretenden garantizar que cada persona tome decisiones libres e informadas sobre el ejercicio de su sexualidad. Esto implica: i) el derecho a conformar una familia bajo un consentimiento libre e informado; ii) el derecho a decidir libremente procrear o no hacerlo, cuándo y con qué frecuencia; iii) el derecho a acceder a información y educación sobre reproducción familiar; iv) el derecho a mantener su fertilidad en igualdad de condiciones que los demás, y v) el derecho a recibir servicios de atención en salud adecuados. La garantía de estos derechos conlleva obligaciones para el Estado de adoptar las medidas pertinentes para que las personas en condición de discapacidad puedan, a través de la asistencia necesaria, ejercer su sexualidad y libertad de manera plena.

Es de resaltar que los derechos sexuales y reproductivos de las mujeres y niñas en condición de discapacidad son vulnerados en mayor medida

en su art. 6 establece que «cuando se trate de discapacitados mentales, la solicitud y el consentimiento serán suscritos por el respectivo representante legal, previa autorización judicial».

13 Como la Declaración Universal de los Derechos Humanos de 1948, el Pacto Internacional de Derechos Civiles y Políticos de 1976, la Convención internacional para la eliminación de todas las formas de discriminación contra la mujer de 1981 y la Convención sobre los Derechos del Niño de 1990. 
(Frohmader y Ortoleva, 2013). Las mujeres afrontan una doble discriminación, la proveniente del género y la de la discapacidad que padecen. Las barreras que afrontan las mujeres y niñas en condición de discapacidad son mayores que aquellas que afrontan las mujeres en general o los hombres en condición de discapacidad. Tener en cuenta la relación entre ambos factores permite entender los tipos de violencia que muchas veces tienen que padecer, entender sus consecuencias y buscar sus posibles soluciones o maneras de prevenirla (Gómez, 2014).

Las mujeres en condición de discapacidad sufren una constante exclusión por parte de la sociedad y ello las hace más proclives a ser víctimas de violencia de diversa índole y origen (Cruz, 2004). La violencia ocurre en distintos ámbitos como en el hogar, muchas veces por la persona que tiene su representación o se encarga de darle cuidados; al interior de la comunidad en la que habitan; y por instituciones estatales o privadas, entre otras. Así mismo, la forma de la violencia puede ser física; psicológica, al lesionar su autoestima; sexual, cuando se impide la maternidad, en casos de esterilizaciones o abortos forzados, cuando no se les proporciona la información y educación sexual; institucional, al no existir políticas que las tengan en cuenta o al negarles información sobre la forma de ejercer sus derechos y al ser estereotipadas y excluidas (Frohmader y Ortoleva, 2013).

Una de las formas más significativa y lesiva de ejercer violencia contra las mujeres en condición de discapacidad es a través de la negativa de proporcionar información clara, accesible y adecuada para la edad de la persona sobre sus derechos sexuales y reproductivos y, la negativa al acceso a programas y servicios de educación sexual, reproducción familiar y anticoncepción, entre otros. Esto les dificulta la identificación de situaciones de violencia, y conocer la forma de afrontarla y denunciarla, de modo que muchas veces no es denunciada y se perpetran más ciclos de violencia (Gómez, 2014).

La importancia de la sentencia T-573 de 2016 de la Corte Constitucional colombiana radica en el reconocimiento de la capacidad jurídica de las mujeres en condición de discapacidad, es decir, de la autonomía para tomar sus propias decisiones sobre el ejercicio de sus derechos sexuales y reproductivos, apartándose de su propia jurisprudencia. Y constituye un paso importante en la lucha por evitar todos estos tipos de violencia en contra de la mujer con diversidad funcional, los cuales hacen imperativa la observancia de la Convención y la adopción de medidas que erradiquen los sistemas de sustitución del consentimiento. Al respecto, es importante destacar la exigencia de la Corte de que la información sea dada en lenguaje sencillo y que sea brindada por equipos multidisciplinarios para asegurar que la comprensión de la mujer al momento de prestar su consentimiento sea completa, la cual se concreta en la 
orden impartida al Ministerio de Educación para que realice la traducción de la sentencia bajo análisis.

En este orden de ideas, la existencia del proceso de interdicción que muchas veces no cumple con su finalidad y se convierte en un instrumento que despoja a las mujeres con diversidad funcional de su capacidad jurídica y las expone a situaciones de violencia, en desmedro de su dignidad humana resulta absolutamente custionable. Adicionalmente, es relevante destacar la anotación que hace Gomiz (2016) sobre cómo los motivos por los que se acude a los procesos de interdicción difieren entre hombres y mujeres. El autor señala que usualmente el proceso de interdicción que se inicia para declarar incapaz a un hombre tiene como objetivo proteger su patrimonio, mientras que en el caso de las mujeres se busca autorizar esterilizaciones que no cuentan con el consentimiento de ellas. La vulneración de la capacidad jurídica de las mujeres se ve aún más afectada cuando del ejercicio de sus derechos sexuales y reproductivos se trata, lo que las expone a una mayor violencia física, psicológica, sexual e institucional.

Esta sentencia es un caso de cumplimiento de la Convención, específicamente de la obligación de eliminar todas las formas de sustitución de decisiones o que pretendan impedir el ejercicio libre e informado de su sexualidad a las mujeres en condición de discapacidad. El reemplazo del proceso de autorización judicial para la esterilización por programas o asesorías en la toma de las decisiones relacionadas con su vida y salud sexual constituye un punto de partida importante en la protección de los derechos de las mujeres en condición de discapacidad y para desaparecer la incongruencia que existe entre el ordenamiento jurídico colombiano y la Convención.

Si bien la importancia de esta sentencia es mayor, para que los derechos de todas las mujeres en condición de discapacidad sean garantizados en Colombia, es necesario vencer los estereotipos sociales y la discriminación a través de la creación de políticas y programas de asistencia para la toma de decisiones relacionadas con su vida y salud sexual, que se encarguen principalmente de brindar información completa, accesible, comprensible sobre el tema y, que se supriman definitivamente en la legislación cualquier modalidad de sustitución del consentimiento.

\section{EL DEBER DE PROTECCIÓN SOBRE LOS SEGUNDOS OCUPANTES EN LOS PROCESOS DE RESTITUCIÓN DE TIERRAS}

En este apartado se presentará el estudio de constitucionalidad efectuado por la Corte Constitucional en la sentencia C-330 de 2016, donde determinó que la exigencia de una buena fe exenta de culpa a los opositores en los 
procesos de restitución de tierras, constituía una discriminación indirecta sobre los segundos ocupantes, cuando estos demostraran condiciones de vulnerabilidad, y no hubieran tenido relación directa o indirecta con el despojo.

La Corte resuelve declarar la exequibilidad de las expresiones acusadas en el entendido de que es un estándar que debe ser interpretado por los jueces de forma diferencial, pues no puede aplicarse del mismo modo a los segundos ocupantes vulnerables que no tuvieron relación con el despojo, como si se tratara de los demás opositores.

\section{LA SENTENCIA C-330 DE 2016}

En la sentencia C-330 de 2016, la Corte tuvo oportunidad de estudiar una demanda de inconstitucionalidad interpuesta por la Asociación Nacional de Usuarios Campesinos (ANUC) ${ }^{14}$ en contra de la expresión «exenta de culpa» contenida en varias disposiciones de la Ley 1448 de $2011^{15}$, también conocida como la ley de víctimas y restitución de tierras.

En criterio del demandante la buena fe exenta de culpa no puede aplicarse sin distinción entre los distintos tipos de personas que pretenden el reconocimiento de una compensación durante el proceso de restitución de tierras, pues ello impone una carga probatoria desproporcionada en situaciones como: i) cuando el opositor, a pesar de no haber actuado de mala fe al momento de acceder al predio objeto de la solicitud, no logra acreditar una debida diligencia informada para no incurrir en error, y ii) cuando el opositor ostenta una condición de vulnerabilidad, situación de pobreza o insatisfacción del derecho a la vivienda y/o subsistencia que le hace acceder al predio.

En ambos escenarios la ley de víctimas y restitución de tierras termina imponiendo una carga probatoria de mayor rigurosidad a los segundos ocupantes que muchas veces no están en posibilidad de desvirtuar. Lo anterior es importante, en especial, porque de ello depende que el juez al fallar pueda reconocerles una compensación económica.

Como la referida ley exige a cualquier persona que se constituya como opositor en los procesos de restitución de tierras, la demostración de una buena fe exenta de culpa ${ }^{16}$, estos segundos ocupantes están en la obligación

14 Creada por medio del Decreto 755 de 1967 dentro de un contexto de políticas dirigidas a fomentar una reforma agraria y resolver los problemas de acceso a tierras del campesinado colombiano.

15 En concreto fueron demandados los arts. 88, 91, 98 y 105.

16 En concreto, el art. 88 establece que: «Al escrito de oposición se acompañarán los documentos que se quieran hacer valer como prueba de la calidad de despojado del 
de superar un estándar probatorio más exigente que el ordinario. De tal forma, en los casos donde no logren demostrar una buena fe exenta de culpa y sean derrotados en juicio, tendrán que entregar el predio objeto de la solicitud a la víctima reclamante sin ninguna contraprestación.

Así, la ANUC sostiene que el legislador cuando aprobó la Ley 1448 de 2011 no tuvo en cuenta cómo dentro de los procesos de restitución de tierras, quienes se oponen a las pretensiones de la víctima, también pueden ser víctimas y estar ocupando los predios abandonados forzadamente que se reclaman en restitución. Esto, según la demanda, desconoce el derecho a la igualdad, a la reparación integral y al deber concreto del Estado de ofrecer alternativas de vivienda digna a otras víctimas.

La Corte Constitucional se ocupó de analizar varios aspectos, entre los cuales se destacan, para los efectos de este escrito, los relativos a: i) el impacto del conflicto armado en el acceso y despojo de tierras; ii) la dimensión constitucional y procedimental del proceso de restitución de tierras, y iii) la discriminación indirecta sobre segundos ocupantes.

En primer lugar, el Alto Tribunal se refirió a los intentos de reforma agraria en 1936, 1961 y 1994 que fracasaron en impulsar una democratización en el acceso a la tierra, y destacó la relación entre el acceso a esta y el conflicto armado interno para señalar que los departamentos ${ }^{17}$ con mayor concentración de propiedad, tienen los índices y cifras más altos de desplazamiento forzado ${ }^{18}$.

El alto nivel de concentración en la propiedad rural ha derivado en su falta de explotación productiva que, aunada a la informalidad en los títulos de propiedad, la falta de unificación de un registro e información catastral desactualizada, persisten como problemas estructurales de la cuestión agraria.

respectivo predio, de la buena fe exenta de culpa, del justo título del derecho y las demás pruebas que pretenda hacer valer el opositor en el proceso, referentes al valor del derecho, o la tacha de la calidad de despojado de la persona o grupo en cuyo favor se presentó la solicitud de restitución formalización».

17 Según lo previsto en el art. 287 de la Constitución, el territorio colombiano se divide en entidades territoriales, que son: municipios, departamentos, distritos y territorios indígenas; y además, las regiones y las provincias que se creen como tales de conformidad con la ley.

$18 \mathrm{Al}$ respecto, es preciso señalar que, según el Informe Anual de Tendencias Globales del Alto Comisionado de las Naciones Unidas para los Refugiados - ACNUR, Colombia es el país con mayor número de desplazados internos en el mundo con alrededor de 6,9 millones de personas. Disponible consulta online: http://www.acnur.org/t3/ fileadmin/Documentos/Publicaciones/2016/10627.pdf. 
Frente al referido diagnóstico, la Corte consideró que la vida campesina ha tenido que desenvolverse en el marco de la ocupación de hecho y la celebración de contratos informales, dentro de un sistema jurídico de sesgo civilista que privilegia la constitución formal de la propiedad privada con base en la inscripción del título ante las oficinas de instrumentos públicos, lo cual ha facilitado el despojo jurídico y, luego material, por parte de la clase terrateniente que sí cuenta con los medios para garantizar su registro. Sobre el particular, acertadamente recoge los informes de ponencia para los debates de la Ley 1448 de 2011, en los cuales se sostuvo:

[...] el despojo asumió varias modalidades, desde las compras forzadas a menor valor hasta el destierro, la usurpación física de la posesión y la destrucción de las viviendas y cercas que delimitaban los predios. El despojo de tierras fue legalizado, muchas veces, con transferencias forzadas, con la participación de notarios y registradores, y el rastro de los despojadores fue borrado por testaferros y múltiples traspasos a terceros de aparente buena fe.

[...] en circunstancias tan irregulares y masivas, la posibilidad de la restitución depende de diseñar un sistema de justicia transicional capaz de restablecer los derechos usurpados por violencia, y para lograrlo requiere contar con normas excepcionales, adecuadas a las modalidades del despojo, que den prelación a los derechos perdidos, aunque cuenten con pruebas precarias y una gran debilidad de defensa legal, sobre los derechos usurpados, pero que ostenten todas las pruebas legales y grandes capacidades de defensa judicial ${ }^{19}$.

En segundo lugar, el Alto Tribunal, en directa relación con lo anterior, destacó el propósito de la acción de restitución de tierras de resarcir un hecho lesivo que va mucho más allá de la relación material de la víctima con el predio, esto es, reconoció el impacto causado por el despojo o abandono de sus tierras en otros derechos como la vivienda digna, la producción alimentaria para garantizarse un mínimo vital y el acceso progresivo a la propiedad rural.

Por tanto, la Corte resaltó el reconocimiento del carácter fundamental del derecho a la restitución, de modo que se entiende como un componente preferente y principal de la reparación integral a las víctimas ${ }^{20}$, además de ser

19 Gaceta 865 de 2010. Proyecto de Ley 107 de 2010 Cámara, acumulado con el Proyecto de Ley 085 de 2010 Cámara. Informe de ponencia para primer debate.

20 La jurisprudencia constitucional colombiana ha relacionado los estándares de protección del derecho a la restitución en el Derecho Internacional de los Derechos Humanos y el Derecho Internacional Humanitario, entre otras, en las Sentencias C-795 de 2014, C-715 y C-820 de 2012. 
una política dirigida a la recomposición del tejido social y la construcción de una paz estable en aquellos territorios más afectados por la guerra.

De esta manera, la acción de restitución incide en una amplia gama de escenarios que constituyen una oportunidad para superar las condiciones históricas de abandono estatal, desigualdad, exclusión y discriminación en materia de derechos económicos, sociales, culturales y ambientales padecidas por la población rural en Colombia.

Por consiguiente, la Corte sostuvo que la estructura probatoria del proceso favorable a las víctimas es constitucionalmente admisible, pues refleja la «imperiosa necesidad de revertir el despojo y develar las distintas maneras de encubrirlo». Al tratarse de una ley pensada para garantizar los derechos de las víctimas, es admisible que en el proceso judicial se invierta la carga de la prueba $^{21}$, y corresponda al opositor desvirtuar el haber participado en los hechos de despojo o ser beneficiario de los mismos ante el juez especializado de restitución de tierras.

Así, el Alto Tribunal expuso que en los procesos de restitución de tierras la buena fe exenta de culpa guarda relación con la eficacia de las presunciones de derecho y legales sobre los predios inscritos en el Registro de Tierras Despojadas y Abandonadas Forzosamente, contenidas en el art. 77 de la Ley 1448 de 2011, que buscan evitar la legalización del despojo y encuentran su fundamento en tres factores inadmisibles constitucionalmente: i) el aprovechamiento de las condiciones de violencia que viciaron el consentimiento de las víctimas; ii) la corrupción que puso parte de la institucionalidad al servicio de los despojadores, y iii) el formalismo del derecho que favoreció a la parte más poderosa ante las autoridades administrativas y judiciales.

Finalmente, la Corte estimó necesario fijar unos parámetros de interpretación partiendo de explicar la figura de la buena fe, en general, y la buena fe exenta de culpa, en particular, como estándar adoptado en el marco transicional de la ley de víctimas y restitución de tierras.

Si bien es cierto que en ambos casos (buena fe simple y buena fe exenta de culpa) el supuesto de obrar con lealtad, rectitud y honestidad se comparte, la buena fe simple es presumida en todas las actuaciones o gestiones que los particulares realizan ante el Estado; mientras que la buena fe exenta de culpa se exige en aquellas circunstancias orientadas a consolidar una consecuencia jurídica determinada, por ello, requiere una mayor cualificación, es decir,

21 El art. 78 de la Ley 1448 de 2011 determina que basta con la acreditación de prueba sumaria de la propiedad, posesión u ocupación y el reconocimiento como desplazado o la prueba sumaria del despojo para que se traslade la carga de la prueba a quienes pretendan oponerse a la pretensión de la víctima en el proceso de restitución. 
eleva el estándar para demostrar la realización de acciones encaminadas a tener certeza de estar obrando de esa forma.

En principio, tratándose de los procesos de restitución de tierras se entiende por qué la exigencia de demostrar una buena fe exenta de culpa para los opositores a la hora del reconocimiento de una compensación; sin embargo, es preciso hacer una distinción entre los distintos tipos de opositores que pueden presentarse con dicha pretensión ante los estrados judiciales, pues no todos están en igualdad de condiciones y, por tanto, deberían recibir un tratamiento diferente.

En este orden, la Corte reseñó que, de acuerdo con el art. 88 de la ley de víctimas y restitución de tierras, existen tres tipos de oposiciones: i) las que persiguen demostrar la calidad de víctima de despojo en relación con el mismo predio objeto de la solicitud de restitución; ii) las dirigidas a tachar la calidad de víctima del solicitante, y iii) las que pretenden demostrar la existencia de una relación jurídica o material sobre el predio reclamado, generada por una conducta calificable de buena fe exenta de culpa. La demanda recae únicamente sobre este último supuesto para demostrar que la exigibilidad de un estándar probatorio tan elevado, cuando se le exige a opositores en situación de vulnerabilidad, les niega el acceso a una compensación económica, sin que haya medidas adecuadas de atención para su situación.

Así el Alto Tribunal identificó que existe una diferencia conceptual entre la categoría genérica de opositores y los denominados segundos ocupantes. Estos últimos, aunque no son una población homogénea, resultan ser quienes ejercen su derecho a la vivienda en los predios que fueron abandonados o despojados forzadamente en el marco del conflicto armado ${ }^{22}$.

Frente a lo anterior, la Corte advirtió una ausencia de medidas afirmativas que se encargaran de abordar el tratamiento de la ocupación secundaria durante el trámite de restitución de tierras, en particular, cuando los segundos ocupantes se encuentran en una condición de vulnerabilidad, surge para el Estado la obligación de brindarles atención prioritaria y plena garantía de respeto a sus derechos frente a los desalojos que encuentra respaldo, entre otros instrumentos internacionales de protección, en los Principios Pinheiro, integrantes del bloque de constitucionalidad ${ }^{23}$ e indispensables para llenar

22 Las razones que los llevan a hacerlo pueden variar desde problemas históricos de inequidad en el reparto de la tierra, hasta ser resultado de estrategias de control territorial por parte de actores armados inmersos en el conflicto.

23 En Sentencia C-035 de 2016, la Corte sostuvo sobre este punto: «Ahora bien, podría ponerse en tela de juicio la incorporación de los Principios Pinheiro y Deng al bloque de constitucionalidad, en la medida en que estos dos instrumentos no consti- 
de contenido las obligaciones estatales referidas al derecho a la restitución de tierras $^{24}$.

Pese al deber jurídico internacional de atender a esta problemática, el legislador guardó silencio sobre la ocupación secundaria en los procesos de restitución de tierras, y determinó la buena fe exenta de culpa como exigencia para todos los opositores que pretendan acceder a una compensación económica en el proceso de restitución de tierras ${ }^{25}$.

De conformidad con lo expuesto, el Alto Tribunal llegó a la conclusión que la medida cuestionada generaba un problema constitucional de igualdad,

tuyen tratados internacionales ratificados por Colombia. En efecto, el artículo 93 de la Constitución Política sostiene que los instrumentos de derechos humanos que prevalecen en el orden interno son los tratados y convenios internacionales ratificados por Colombia. Según esta interpretación, los mencionados principios sólo constituyen recomendaciones sin ningún carácter vinculante. Sin embargo, esta interpretación no resulta aceptable para la Corte. No sólo simplifica indebidamente la jurisprudencia de esta Corporación en materia de incorporación de instrumentos internacionales al bloque de constitucionalidad, sino que desconoce la dinámica propia de la política internacional [...] En esa medida, los tratados sobre derechos humanos suelen tener un lenguaje bastante general, disposiciones ambiguas y conceptos indeterminados, lo cual obedece a la lógica necesidad de articular diferentes visiones y culturas a los tratados sobre derechos humanos. Esto es lo que se ha llamado la textura abierta de los tratados sobre derechos humanos. Por tal motivo, para darle un efecto útil a las disposiciones del bloque de constitucionalidad incorporadas vía artículo 93 de la Constitución Política resulta indispensable contar con instrumentos que le permitan a esta Corporación precisar el contenido y alcance de las disposiciones sobre derechos humanos contenidas en estos tratados internacionales».

24 Así, por ejemplo, el principio 17 establece que en el tratamiento a segundos ocupantes: «[...] los Estados deben velar porque estén protegidos contra el desalojo forzoso arbitrario o ilegal. En los casos en que su desplazamiento se considere justificable e inevitable a los efectos de la restitución de las viviendas, las tierras y el patrimonio, los Estados garantizarán que el desalojo se lleve a cabo de una manera compatible con los instrumentos y las normas internacionales de derechos humanos, proporcionando a los ocupantes secundarios las debidas garantías procesales, incluida la posibilidad de efectuar consultas auténticas, el derecho a recibir una notificación previa adecuada y razonable, y el acceso a recursos jurídicos, como la posibilidad de obtener una reparación».

El art. 91 de la Ley 1448 de 2011, referido al contenido del fallo, establece que el juez deberá dictar las órdenes necesarias para garantizar que las partes de buena fe exenta de culpa vencidas en el proceso sean compensadas, y el art. 98 de esa misma ley estipula que las compensaciones decretadas en la sentencia deben ser a favor de los opositores que probaron la buena fe exenta de culpa, y en ningún caso podrá exceder el valor del predio acreditado en el proceso. 
en razón al tratamiento paritario dado a dos grupos de personas en situaciones disimiles: los segundos ocupantes que se encuentran en situación ordinaria y tuvieron alguna relación o se beneficiaron del despojo; y los segundos ocupantes en condición de vulnerabilidad que no tuvieron ninguna relación con el despojo, ni sacaron de este provecho para sí o para un tercero.

En la medida en que las disposiciones acusadas exigen a todos los opositores demostrar una conducta calificada (buena fe exenta de culpa) y no da un trato diferencial a personas que lo merecen, genera una discriminación indirecta sobre esta última clase de segundos ocupantes. Por tanto, la Corte declaró exequible la expresión "exenta de culpa», en el entendido de que es un estándar que debe ser interpretado por los jueces de forma diferencial, y exhortó a implementar una política pública comprensiva acerca de la situación de los segundos ocupantes en el marco de la justicia transicional.

\section{UNA DECISIÓN GARANTISTA PARA EVITAR UNA LUCHA ENTRE IGUALES}

La decisión adoptada por la Corte resulta muy valiosa porque el tratamiento inadecuado de la problemática de ocupación secundaria ha sido identificado en la experiencia internacional (casos de Kosovo, Bosnia Herzegovina, Ruanda o Azerbaiyán) como uno de los principales factores de riesgo frente a la seguridad jurídica y material para las víctimas en procesos de restitución de tierras (Scott, 2004).

Acertadamente el Alto Tribunal comprendió que el problema jurídico planteado no se trataba de una violación al principio de igualdad derivada de realizar una comparación entre víctimas y opositores, sino entre los opositores que siendo segundos ocupantes se encuentran en condiciones de vulnerabilidad, y los demás tipos de opositores. La ley de víctimas y restitución de tierras al darles un mismo trato y exigirles un mayor estándar probatorio, desconocía el déficit de protección en que se encuentran los primeros y la necesidad de salvaguardar sus derechos.

La necesidad de acotar el alcance de la decisión radica en que una declaratoria de inexequibilidad sobre la expresión «exenta de culpa», conforme había sido solicitada en la demanda, hubiera generado una desprotección de las víctimas reclamantes de tierras, si se tiene en cuenta que este estándar probatorio cualificado guarda relación con las presunciones de despojo contenidas en la ley.

Así, la constitucionalidad condicionada del fallo entiende las peculiaridades del principio de buena fe exenta de culpa en la acción de restitución a la 
luz de los deberes jurídicos de carácter internacional del Estado y coincide con la protección de los segundos ocupantes ya adoptada en su jurisprudencia ${ }^{26}$.

Por último, la Sentencia C-330 de 2016 mantiene el llamado a garantizar el derecho humano a la vivienda y el derecho de acceso progresivo a la propiedad rural ${ }^{27}$ frente a la población víctima desplazada forzadamente que, debido a la falta de una adecuada respuesta institucional, ha tenido que ocupar tierras despojadas o abandonadas forzadamente. De ahí que acierta la Corte en precisar la necesidad de adoptar un enfoque de reparación transformadora en el marco de las medidas de justicia transicional ${ }^{28}$, de manera que los jueces de restitución de tierras al momento de ordenar las reparaciones, además de tener un carácter restitutivo, contribuyan a superar las condiciones de marginalidad y exclusión que precisamente hicieron que esas fueran las víctimas desplazadas forzadamente y no otras.

Sin duda, se requiere que la restitución de tierras sea acompañada de órdenes complementarias dirigidas a garantizar vivienda, salud, agua potable, educación, entre otras condiciones materiales dignas, no solo para las familias reclamantes en los predios restituidos como garantías de no repetición (Cifuentes, 2017), sino demás impulsar políticas públicas de atención frente al reconocimiento de los derechos de los segundos ocupantes en condiciones de vulnerabilidad, en desarrollo del mandato de igualdad, y específicamente, del principio de no discriminación.

\section{Bibliografía}

Alto Comisionado de las Naciones Unidas para los Refugiados - ACNUR. Informe Anual Tendencias Globales. Desplazamiento forzado en 2015. Forzados a Huir. Disponible en:http://www.acnur.org/t3/fileadmin/Documentos/Publicaciones/2016/10627.pdf.

26 En Sentencia C-795 de 2014, la Corte sostuvo que en el marco de la justicia restitutiva y de la plena satisfacción del derecho a la reparación, es muy importante la protección de los derechos de los segundos ocupantes frente al desalojo forzoso, arbitrario e ilegal que puede llegar a producirse para garantizar de forma efectiva el derecho a la restitución de las víctimas de despojo y abandono favorecidas con la sentencia.

27 El art. 64 de la Constitución Nacional establece como deber del Estado promover el acceso progresivo a la propiedad de la tierra de los trabajadores agrarios, en forma individual o asociativa, con el fin de mejorar el ingreso y calidad de vida de los campesinos.

28 Este enfoque propuesto por Uprimny, R. y Sánchez, C. (2010) surge de la iniciativa de articular la justicia correctiva y la justicia distributiva en el diseño y la implementación de los programas de reparación e implica que, además del resarcimiento del daño, estas medidas deben buscar la superación de las causas estructurales del conflicto. 
Arnau, S. (2014). La asistencia sexual a debate. Dilemata, 6 (15), 7-14.

Asamblea General de la Naciones Unidas. Convención sobre los Derechos de las Personas con Discapacidad, 13 de diciembre de 2006. Disponible en: http://www.un.org/ esa/socdev/enable/documents/tccconvs.pdf.

Cifuentes, S. (2017). Desplazamiento forzado y restitución de tierras en Colombia: una búsqueda de garantías de no repetición frente a una práctica de guerra para la acumulación. Verba Iuris, 37, 91-108.

Cruz, M. P. (2004). Mujeres con discapacidad y su derecho a la sexualidad. Politica y Cultura, 22, 147-160.

Frohmader, C. y Ortoleva, S. (2013). The Sexual and Reproductive Rights of Women and Girls with Disabilities. Issues Paper: International Conference on Human Rights, 2-9. Disponible en: http://wwda.org.au/wp-content/uploads/2013/12/issues_ paper_srr_women_and_girls_with_disabilities_final.pdf.

Gómez, V. (2014). Análisis de la discapacidad desde una mirada crítica: Las aportaciones de las teorías feministas. Estudios Pedagógicos XL, 2, 391-407. Disponible en: https://doi.org/10.4067/S0718-07052014000300023.

Gomiz, M. P. (2016). La sexualidad y la maternidad como factores adicionales de discriminación (y violencia) en las mujeres con discapacidad. Revista Española de Discapacidad, 4 (2), 123-142. Disponible en: https://doi.org/10.5569/23405104.04.02.07.

PAIIS, et al. (2014). Capacidad jurídica, derechos sexuales y derechos reproductivos de las mujeres con discapacidad intelectual y con discapacidad psicosocial en Colombia. Proyecto: Derecho a la autonomía sexual y reproductiva de mujeres con discapacidad intelectual y psicosocial en Colombia 2012-2014. Bogotá.

Pons, J. y Sánchez, J. (2017). Capacidad jurídica de personas con discapacidad: contexto mexicano en el derecho civil. Perfiles de las Ciencias Sociales, 4 (1), 1-31. Disponible en: http://revistas.ujat.mx/index.php/perfiles.

Scott, L. (2004). Nuevas tendencias en la restitución de la vivienda y la propiedad. El otro derecho, 31-32.

Uprimny, R. y Sánchez, C. (2010). Propuestas para una restitución de tierras transformadora. En L. Villa Arcila, et. al. Temas pendientes: propuestas para la formulación de políticas públicas de reparación en Colombia. Bogotá: Centro Internacional para la Justicia Transicional — ICTJ. 